suggesting, if anything, the presence of a low level of D in Group SUN. The nonsignificantly slower latencies for Group SUN across all trial blocks could be viewed as being consistent with such an interpretation. The significant trial blocks effect in the latency analysis, together with the nonsignificant Groups by Trial Blocks interaction, indicates that both groups were becoming less attentive across trials.

Finally, the significant main effect for groups in the duration analysis, considered in conjunction with the other findings, suggests that the Ss in Group SUN were making relatively prolonged responses as a means of providing themselves with additional stimulation (presumably kinesthetic in nature). Note that the duration function for Group CCM is a flat one, whereas that for Group SUN increases monotonically across trial blocks, suggesting a Groups by Trial Blocks interaction (see Fig. 1). The failure to obtain a significant interaction in the analysis of variance was doubtless due to the extreme variability of the duration data.

While it is tempting to consider the possibility that the groups effect in the duration data signifies greater energization for Group SUN, the amplitude results are clearly not consistent with such a view. One might wish to argue that the meaningful pictures selected for presentation to Group CCM did not have the "interest value" they were assumed to have for those Ss, and thus, in a functional sense, Groups SUN and CCM were not treated differently. It would not seem, however, that such a position could be easily reconciled with the significant groups main effect in the duration data and the consistency in the direction of differences across all trial blocks in the amplitude and latency data.

Taking the present results in conjunction with those of earlier studies in the series, one must conclude we have been singularly unsuccessful in demonstrating the energization effect predicted by Fowler's theory. Perhaps the theory does not apply to children's behavior. Alternatively, perhaps the experimental manipulations we have employed have not been sufficiently powerful and/or our dependent measures have been inappropriately selected. Still another possibility is that the theory is wrong and that repetitious, simple stimulation actually leads to a low level of D (see especially Cantor, 1968, and Fenson, 1968, for evidence consistent with the latter view).

\section{REFERENCES}

CANTOR, G. N. Effects of a "boredom" treatment on children's simple RT performance. Psychonomic Science, 1968, 10, 299-300.
IENSON, L. Effects of two types of repetitive and nonrepetitive stimulation on children's response speeds. Unpublished doctoral dissertation, University of Iowa, 1968.

FOWLER, H. Satiation and curiosity: Constructs for a drive and incentive-motivational theory of exploration. In K. W. Spence and J. T. Spence (Eds.), The psychology of learning and motivation. Vol. 1. New York: Academic Press, 1967. Pp. 157-227.

KUBOSE, S. K. Effects of type and duration of visual stimulation on children's motor task response speeds. Unpublished doctoral dissertation, University of Iowa, 1969.

RABINOWITZ, F. M. Conditioned stimulus duration and delay of reward as variables in a lever pulling situation. Journal of Experimental Child Psychology, 1966, 3, 225-234

SPENCE, K. W. Behavior theory and conditioning. New Haven: Yale University Press, 1956.

\title{
Disruption of short-term memory in man following consumption of ethanol*
}

\author{
RALPH S. RYBACK $\dagger$ \\ Boston City Hospital and Harvard Medical School, Boston, Mass. 02115 \\ and \\ JANE WEINERT and JAMES L. FOZARD \\ Psychiatry Research Department, Massachusetts General Hospital, Boston, Mass. 02114
}

Over a 45-min period, accuracy of recognition of previously presented pictures systematically decreased in 10 nonalcoholics after a moderate amount of alcohol was consumed. The decline in performance was relatively greater when the number of pictures between the old picture and its question was larger, suggesting that alcohol affected retrieval as well as attention mechanisms.

In terms of threefold classification of memory function (Shuttleworth \& Morris, 1966), alcohol amnesia seems to be a type of short-term or intermediate-level memory deficit, usually associated with a prolonged acute or relatively acute rise in the blood alcohol concentration. There is less difficulty with immediate or with long-term or remote memory (Ryback, 1969, 1970a, b). The present study investigated the effects of alcohol on short-term memory in one task (Fozard \& Yntema, 1966) in which performance does not appear to depend importantly on an individual's proficiency or adaptability to it (Carpenter \& Ross, 1963).

\section{MATERIALS AND METHODS}

Ss inspected a long sequence of single colored pictures of animals, food, implements, persons, plants, or other objects. They were drawn from a set of 1,600 ; some were copies of those used by Shepard (1967). After every two inspection pictures, a question containing two pictures was presented. In some questions one of the two pictures had been presented earlier in the experiment and the other had not; the S's task was to select the previously presented picture, i.e., recognize the "old" picture. After its presentation in

*Paper presented at the AAAS, Boston, Massachusetts, Dec. 29, 1969. Supported in part by National Science Foundation Grant GB7837 to the Massachusetts General Hospital and V.A. Outpatient Clinic and in part by NIMH Grant No. 09245 to the Alcohol Study Unit, Boston City Hospital.

† Present address: McLean Hospital, Belmont, Mass. 02178. a question, a picture was not shown to the $S$ again. In other questions both pictures had been presented earlier in the experiment, and the $\mathrm{S}$ selected the picture he believed had been presented more recently. Only the data from the first of the two tasks are described here.

The number of items separating the initial presentation of a picture from its question took on one of four average values. The smallest separation was 24 or 25 items (24.5). The others were 48.5 , 96.5 , and 192.5 items. This count included items in earlier questions as well as new items. Sequences of stimuli and questions were photographed on $16-\mathrm{mm}$ color film and presented to each $S$ by means of a movie projector adapted for single frame advance. The experiment was entirely S-paced.

The Ss were five male and nine female undergraduates and medical students, 21-29 years of age. The 10 experimental Ss received $1.2 \mathrm{cc} / \mathrm{kg}$ of body weight of $95 \%$ ethanol diluted with $300 \mathrm{ml}$ of orange juice, which they consumed with in $30 \mathrm{~min}$. The four control Ss received an equal volume of orange juice but with $1 \mathrm{cc}$ of $95 \%$ ethanol. Ss were not told whether they were in the experimental or control group, and all had not eaten for at least $4 \mathrm{~h}$.

At the beginning of the experiment, all Ss received practice trials followed by test trials to establish a base level of performance. After the drinking period, Ss resumed the experiment. After 30 and $45 \mathrm{~min}$ of testing, their blood alcohol level was determined by a breathalyzer. ${ }^{1}$ The 


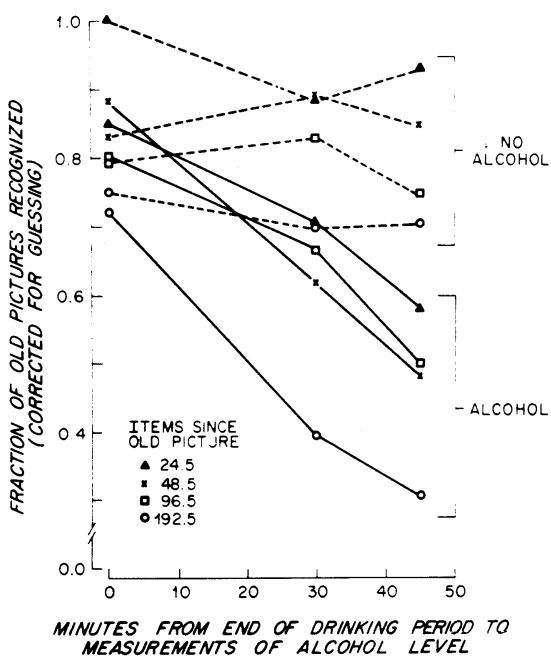

Fig. 1. Average recognition of previously presented pictures before $(0 \mathrm{~min})$ and at two times after (30 and $45 \mathrm{~min})$ consumption of alcohol.

entire experiment lasted about $90 \mathrm{~min}$. The average time to inspect two pictures and answer one question was $11.1 \mathrm{sec}$.

\section{RESULTS}

Figure 1 shows the fraction of correct recognition of previously presented items (corrected for guessing between two alternatives) for the experimental and control groups before drinking (0), and 30 and $45 \mathrm{~min}$ after testing had been resumed following the ingestion of alcohol. The data at " 0 " are the mean of each S's average performance for 12 questions at each of the four separations; those at 30 and $45 \mathrm{~min}$ are based on the average of his responses to the five questions preceding and the five following the two breathalyzer tests.

The data above " 0 " on the horizontal axis of Fig. 1 show that except for the control Ss, who made no errors of recognition for pictures 24.5 items back in the list, there were no systematic differences in performance between the experimental and control Ss prior to ingestion of alcohol.

Over the course of the experiment, recognition performance declined in the experimental group, but not in the control group. Results of a Friedman analysis of variance for ranks performed on the averages of the experimental Ss' performance over the four question types at the three testing times indicated a statistically significant decline, $\mathrm{X}_{\mathrm{r}}^{2}(3)=10.4, \quad \mathrm{p}<.02$. Subsequent applications of the sign test showed that the declines between 0 and $45 \mathrm{~min}$ for 96.5 items $(p=.02)$ and 0 and $30 \mathrm{~min}$ for 192.5 items $(p=.055)$ were statistically significant.

\section{DISCUSSION}

The magnitude of the decline in recognition performance associated with alcohol was larger than that typically produced by other operations which impair recognition, e.g., shortened presentation times or the use of words as opposed to pictures as the test materials (Yntema \& Trask, 1963; Fozard \& Lapine, 1968).

The decline of recognition performance in the experimental group was not related to the Ss' sex but was accompanied by an overall increase in blood alcohol level. At the $30-$ and $45-\mathrm{min}$ testing periods, respectively, the average blood alcohol level was $79 \mathrm{mg} \%(79 \mathrm{mg} / 100 \mathrm{ml})$ with a range of 40 to $110 \mathrm{mg} \%$, and $103 \mathrm{mg} \%$ with a range of 80 to $130 \mathrm{mg} \%$, respectively, for experimentals and zero for controls.

Individual differences in the amount of decline in recognition performance of the experimental Ss were large, as the overall recognition performance of four Ss was only mildly affected. There was little systematic relationship between recognition performance and the observed absolute level of alcohol, perhaps because the alcohol dose given was relatively low and did not produce a high mean blood alcohol level.

An important factor which may have been associated with differences in performance among the experimental Ss was their experience with alcohol (Goldberg, 1943). Three of the four whose performance was mildly affected considered themselves "moderate" drinkers (e.g., parties and predinner cocktails); in contrast, three of the four poorest performing experimental Ss considered themselves infrequent drinkers (e.g., occasional drinks at parties).

Figure 1 shows that in both the control and experimental groups, failures of recognition increased as the number of items from an old picture to its question increased. The average differences across the three test values were statistically significant only in the experimental group, $\mathrm{X}_{\mathrm{r}}^{2}(4)=43.8, \mathrm{p}<.001$. Applications of the sign test to pairs of differences at the 30 - or $45-\mathrm{min}$ testing times showed that performance for 192.5 items was worse than that of any of the others $(p=.02$ or $.055)$. These data therefore suggest that registration or perception of the pictures was not the only factor affected by alcohol; retrieval of the older item was also affected.

After 30 to $45 \mathrm{~min}$ of testing, there was a differentiation between recognition of items seen 1 to 4 min previously (24.5-96.5 items) when memory was still relatively intact and those seen about 9 min earlier (192.5 items) when memory was relatively impaired. Figure 1 suggests that performance worsens gradually. Again. in terms of recent distinctions between immediate, short-term, and long-term memory (Shuttleworth \& Morris, 1966), the present data also suggests that short-term memory seems to be most seriously affected by alcohol.

Mechanisms for the relatively greater effects of alcohol on memory for the older items, including possible effects on the hippocampus and limbic systems. have been discussed elsewhere (Ryback, 1969, 1970a, b). Empirically, the findings of this and previous experiments may help in part to explain the chatter observed at cocktail parties with participants jumping from one topic to another because they forgot what they were talking about, where they were in the conservation, or what the other person said. It may also help one understand why people with alcohol amnesia, as those with hippocampal lesions, cannot recall whether they have eaten lately or what they said 5 min earlier (Ryback, 1969, 1970a, b).

\section{REFERENCES}

CARPENTER, J. A., \& ROSS, B. M. Effect of alcohol on short-term memory. Quarterly Journal of Studies on Alcohol, 1963, 21, 561-579.

DRACHMAN, D. A., \& ARBIT, J. Memory and the hippocampal complex. Archives of Neurology, 1966, 15, 52-61.

FOZARD, J. L., \& LAPINE, R. Comparison of discrimination of recency of pictures and names of common objects. American Psychologist, 1968, 23, 658-662.

FOZARD, J. L., \& YNTEMA, D. B. The effect of repetition on the apparent recovery of pictures. American Psychologist, 1966, 21 873.

GOLDBERG, L. Quantitative studies on alcohol tolerance in man: The influence of ethyl alcohol on sensory, motor, and psychological functions referred to blood alcohol in normal and habituated individuals. Acta Psychiatrica Scandinavica, 1943, 5, 7-143.

RYBACK, R. The use of goldfish as a model for alcohol amnesia in man. Quarterly Journal of Studies on Alcohol, 1969, 30, 877-882.

RYBACK, R. Alcohol amnesia. Journal of the American Medical Association, 1970a, 212, 1524.

RYBACK, R. Alcohol amnesia: Observations on seven inpatient drinking alcoholics. Quarterly Journal of Studies on Alcohol, 1970b, 31, 616-632.

SHEPARD, R. N. Recognition memory for words, sentences, and pictures. Journal of Verbal Learning \& Verbal Behavior, 1967, 6 , 156-163.

SHUTTLEWORTH, W. C., \& MORRIS, C. E. The transient global amnesia syndrome. Archives of Neurology, 1966, 15, 515-520.

YNTEMA, D. B., \& TRASK, F. A. Recall as a search process. Journal of Verbal Learning \& Verbal Behavior, 1963, 2, 65-74. NOTE

1. Breathalyzer made by Stevenson Corporation. Redbank. N.Y. 